\title{
Specific patterns of genetic diversity among aromatic rice varieties in Myanmar
}

\author{
Khin Myo Myint ${ }^{1,4}$, Brigitte Courtois ${ }^{2 *}$, Ange-Marie Risterucci ${ }^{2}$, Julien Frouin ${ }^{2}$, Khin Soe ${ }^{3}$, Khin Maung Thet ${ }^{1}$, \\ Apichart Vanavichit ${ }^{4}$ and Jean-Christophe Glaszmann ${ }^{2}$
}

\begin{abstract}
Background: After observing peculiar rice varieties in Myanmar, in terms of classification in varietal groups and of grain quality, we focused on Myanmar varieties and analyzed variations at 19 microsatellite loci as well as sequences of the aroma gene BADH2.

Results: Microsatellites were able to retrieve the well-established classification into Indica (isozyme group 1), Japonica (group 6, comprising temperate and tropical forms) and specific groups from the Himalayan foothills including some Aus varieties (group 2) and some aromatic varieties (group 5). They revealed a new cluster of accessions close to, but distinct from, non-Myanmar varieties in group 5. With reference to earlier terminology, we propose to distinguish a group " $5 \mathrm{~A}$ " including group 5 varieties from the Indian subcontinent (South and West Asia) and a group " $5 \mathrm{~B}$ " including most group 5 varieties from Myanmar. In Myanmar varieties, aroma was distributed in group 1 (Indica) and in group 5B. New BADH2 variants were found. Some accessions carried a 43 bp deletion in the $3^{\prime}$ UTR that was not completely associated with aroma. Other accessions, all of group 5B, displayed a particular BADH2 allele with a 3 bp insertion and 100\% association with aroma.
\end{abstract}

Conclusion: With the new group and the new alleles found in Myanmar varieties, our study shows that the Himalayan foothills contain series of non-Indica and non-Japonica varietal types with novel variations for useful traits.

Keywords: Oryza sativa, SSR, Genetic diversity, Aroma, BADH2

\section{Background}

Rice is the main cereal consumed by humans. Oryza sativa, the main rice species grown in the world, grows in a very wide range of ecological conditions all over the world and encompasses an extremely wide diversity; more than 106,800 accessions are stored in the International Rice Genebank in the Philippines (de Guzman, IRRI, personal communication).

The organization of $O$. sativa diversity has been of major interest for rice scientists since the early $20^{\text {th }}$ century, beginning with the pioneering work of Kato et al. (1928), Matsuo (1952), and Oka (1958). The development of genetic markers, first enzymatic then DNA-based, enabled further refinement of the original classification (Glaszmann 1987; Garris et al. 2005). According

\footnotetext{
* Correspondence: brigitte.courtois@cirad.fr

${ }^{2}$ Cirad, UMR AGAP, Avenue Agropolis, 34398 Montpellier, France

Full list of author information is available at the end of the article
}

to generally accepted knowledge, $O$. sativa accessions can be classified in two main groups, the indica group (isozyme group 1), which includes most tropical irrigated and rainfed lowland varieties, and the japonica group (isozyme group 6), a group with a wider range of agroecological adaptations. From a genetic viewpoint, the japonica group can be divided into a temperate component comprising irrigated varieties, and a tropical component comprising upland and high elevation varieties, although morphological studies showed that the two components represented a continuum (Glaszmann and Arraudeau 1986). In addition to these two major groups, two smaller groups were identified: the aus/boro group (isozyme group 2) comprising varieties from South Asia, and the sadri/ basmati group (isozyme group 5) comprising irrigated varieties from all along the Himalayan border from Iran to Myanmar, including the world famous basmati rices from India and Pakistan and sadri from Iran (Glaszmann 1987). Additional groups such as deepwater rices from 
India and Bangladesh (enzymatic group 3) and rayada floating rices from Bangladesh (isozyme group 4) were identified in isozyme studies (Glaszmann 1987) but not confirmed with other markers. One possible reason for this discrepancy could be their under-representation in the samples analyzed, which in turn, may be explained by the small number of such accessions and the difficulties involved in obtaining seeds of these highly photoperiodic varieties.

Wide phenotypic diversity accompanies genetic diversity for all types of traits including grain characteristics. Rice is consumed mostly as cooked grain with little processing, and grain appearance, cooking quality, and taste are the factors that determine grain quality. Aromatic varieties are particularly appreciated by consumers in some countries and, for this reason, fetch a much higher price than nonaromatic varieties on these markets (Unnevher et al. 1992; Singh et al. 2000; Juliano 2007). Aroma in rice grain results from the production of many biochemical compounds (Petrov et al. 1996) of which the most important is 2-acetyl-1- pyrroline (Buttery et al. 1982). The presence of this molecule is genetically determined, but the intensity of this volatile compound is very much affected by the conditions of grain maturation and storage (Singh et al. 2000; Fitzgerald et al. 2008; Gay et al. 2010). Although the chemical pathway leading to the production of acetylpyrroline is not yet fully understood, a recessive gene annotated as a betaine aldehyde dehydrogenase (BADH2) located on chromosome 8 has been shown to play a key role in its synthesis (Bradbury et al. 2005, Bradbury et al. 2008, Vanavichit et al. 2008). Non-functional alleles of $B A D H 2$ result in the accumulation of acetyl-pyrroline (Chen et al. 2008; Niu et al. 2008). The diversity of this gene has been studied in a large collection of varieties and results showed that an 8 bp deletion in the seventh exon of $B A D H 2$ causing a reading frame shift was present in most aromatic accessions, but other less frequent mutations associated with aroma were also detected (Bradbury et al. 2005; Bourgis et al. 2008; Shi et al. 2008; Kovach et al. 2009; Sakthivel et al. 2009).

Although aromatic varieties can be found in isozymic groups 1, 5 and 6, their frequency is much higher in group 5 (Singh et al. 2000). Glaszmann (1987, 1988) reported that a high proportion of Myanmar varieties belonged to group 5 and that some of these were peculiar in terms of allelic combination, notably at isozyme locus Amp3 on chromosome 6, as well as in terms of grain quality. Myanmar occupies a key geographic position at the interface between South and South-East Asia. Myanmar is geographically diverse with four recognizable regions (the Ayeyarwady delta, a coastal strip, the central dry plain and mountain ranges). Rice is an important crop for Myanmar, which has the highest per capita consumption of rice in the world: more than
$210 \mathrm{~kg}$ per person per year. Rice cultivation covers eight million hectares (http://faostat.fao.org, 2009), mainly rainfed lowland rice (54\% of the area), but also deepwater rice $(24 \%)$ irrigated rice (18\%), and upland rice (6\%) (IRRI, 2002). Because of the interface position and ecological diversity of Myanmar, the genetic diversity of Myanmar rice varieties is expected to be high.

Studies on the diversity of sets of varieties from Myanmar have already been conducted using isozymes (Khush et al. 2003; Tun 2006) but seldom with molecular markers (Yamanaka et al. 2011) and never with a focus on aromatic accessions. Accessions from Myanmar were not widely represented in the worldwide genetic studies conducted so far (Garris et al. 2005; Kovach et al. 2009).

The objective of this study was to characterize the genetic diversity of a collection of Myanmar varieties, notably those belonging to group 5 and those known to be aromatic, and to relate it to the diversity observed in the $B A D H 2$ gene.

\section{Methods}

\section{Material}

The 147 varieties from Myanmar we analyzed are listed in Table 1. A first subset of 96 accessions including 62 aromatic and 34 non-aromatic varieties originating from different geographical regions in Myanmar were provided by the Myanmar Seed Bank ("MSB" ID prefix). The isozyme group to which these accessions belonged was unknown. The second subset of 51 accessions including 3 aromatic, 45 non aromatic and 3 varieties with undetermined fragrance from Myanmar were provided by IRRI Genebank ("IRGC" ID prefix). According to the results of Khush et al. (2003), all the members of the second subset belong to isozymic group 5. The aromatic/non aromatic quality of the varieties had already been determined by the Myanmar Seed Bank based on sensory tests. The sensory tests, based on leaf samples, were repeated for confirmation (Myo Myint, personal results) following the protocol of Sood and Siddiq (1978).

We complemented this set with 80 varieties listed in Additional file 1: Table S1 extracted from a core collection representing the varietal group diversity of Oryza sativa for which the enzymatic group had already been determined (Glaszmann et al. 1995). This set, hereafter referred to as "reference set", was composed of 20 accessions from group 1 (indica), 9 from group 2 (aus/boro), 31 from group 5 (sadri/basmati), and 20 from group 6 (japonica), so group 5 accessions were over-represented. The information on the aromatic/non-aromatic nature of these accessions came from Kovach et al. (2009) and, for those that were not tested by these authors, from breeders' knowledge (Additional file 1: Table S1). Those 
Table 1 List of the 147 Myanmar accessions assayed

\begin{tabular}{|c|c|c|c|c|c|c|c|c|c|}
\hline ID & Variety name & Region of origin & Ecosystem & EG & $\begin{array}{l}\text { Structure } \\
\text { group }\end{array}$ & Aroma & $\begin{array}{l}\text { Genotype } \\
8 \text { bp del. }\end{array}$ & $\begin{array}{l}\text { Genotype } \\
3 \text { bp ins. }\end{array}$ & Haplotype \\
\hline MSB_1158 & BAHAN HMWE & Ayeyarwady Division & $\mathrm{RL}$ & u & 1 & $\mathrm{Ar}$ & $P$ & $A$ & $\mathrm{H} 1$ \\
\hline MSB_1774 & BAY KYAR & Sagaing Division & $R L$ & u & $\mathrm{m}$ & $\mathrm{Ar}$ & A & A & $\mathrm{H} 12$ \\
\hline MSB_3708 & BAY KYAR PAW SAN & Yangon Division & $\mathrm{RL}$ & u & $5 B$ & $\mathrm{Ar}$ & A & $P$ & $\mathrm{H} 5$ \\
\hline MSB_325 & CHIN KAUK HNYIN & Sagaing Division & u & u & 1 & $\operatorname{Ar}$ & A & A & $\mathrm{H} 7$ \\
\hline MSB_1898 & EMAHTA HMWE & Kachin State & $\mathrm{RL}$ & u & 1 & $\mathrm{Ar}$ & A & A & $\mathrm{H} 7$ \\
\hline MSB_2297 & KAMAR KYI SAW & Mon State & $\mathrm{RL}$ & u & $5 B$ & $\operatorname{Ar}$ & A & $P$ & $\mathrm{H} 5$ \\
\hline MSB_6071 & KAUK HNYIN HMWE & Shan State & u & u & 1 & $\mathrm{Ar}$ & $P$ & A & $\mathrm{H} 1$ \\
\hline MSB_6108 & KAUK HNYIN NET & Shan State & u & u & $5 B$ & $\operatorname{Ar}$ & A & $P$ & $\mathrm{H} 5$ \\
\hline MSB_6097 & KAUK HNYIN PHYU & Shan State & u & u & $5 B$ & $\operatorname{Ar}$ & A & $P$ & $\mathrm{H} 5$ \\
\hline MSB_371 & KAUK HNYIN SAW & Kachin State & u & u & 1 & $\mathrm{Ar}$ & u & $A$ & ns \\
\hline IRGC_58069 & KYET PAUNG & Semi-arid zone & u & 5 & $5 \mathrm{~A}$ & $\mathrm{Ar}$ & $P$ & A & $\mathrm{H} 1$ \\
\hline MSB_235 & KYET PAUNG SAN & Sagaing Division & $\mathrm{RL}$ & u & 1 & $\mathrm{Ar}$ & A & A & $\mathrm{H} 7$ \\
\hline MSB_1932 & KYWET THWAR & Yangon Division & u & u & 1 & $\mathrm{Ar}$ & A & A & $\mathrm{H} 10$ \\
\hline MSB_7293 & MAN AUNG KAUK YIN & Rakhine State & u & u & $5 B$ & $\operatorname{Ar}$ & A & A & $\mathrm{H} 4$ \\
\hline MSB_398 & MEE DON YIN & Mandalay Division & u & u & $5 B$ & $\mathrm{Ar}$ & A & A & $\mathrm{H} 3$ \\
\hline MSB_829 & MYA WAR NGA CHEIK & Sagaing Division & u & u & 1 & $\mathrm{Ar}$ & u & A & $\mathrm{H} 6$ \\
\hline MSB_2283 & NAMATHALAY & Sagaing Division & u & u & $5 \mathrm{~A}$ & $\mathrm{Ar}$ & $P$ & A & $\mathrm{H} 1$ \\
\hline MSB_1809 & NAT PYI HMWE & Bago Division & u & u & $5 B$ & $\operatorname{Ar}$ & u & u & $\mathrm{H} 4$ \\
\hline MSB_1382 & NGA BYA YIN KAUK HNYIN NET & Sagaing Division & u & u & $5 B$ & $\operatorname{Ar}$ & A & $P$ & $\mathrm{H} 5$ \\
\hline MSB_1777 & NGA CHEIK & Kachin State & u & u & $5 B$ & $\operatorname{Ar}$ & A & A & $\mathrm{H} 4$ \\
\hline MSB_5884 & NGA CHEIK & Chin State & u & u & 1 & $\operatorname{Ar}$ & A & A & $\mathrm{H} 13$ \\
\hline MSB_6101 & NGA CHEIK KAUK HNYIN & Shan State & u & u & 1 & $\operatorname{Ar}$ & A & A & ns \\
\hline MSB_1790 & NGA KYWE & Bago Division & $\mathrm{RL}$ & u & 1 & $\mathrm{Ar}$ & u & A & ns \\
\hline MSB_56 & NGA KYWE & Mon State & $R L$ & u & $5 B$ & $\operatorname{Ar}$ & A & A & $\mathrm{H} 2$ \\
\hline MSB_1105 & NGA KYWE (U TO) & Ayeyarwady Division & $\mathrm{RL}$ & u & $5 B$ & $\operatorname{Ar}$ & A & A & ns \\
\hline MSB_1638 & NGA KYWE NOTE & Bago Division & $\mathrm{RL}$ & u & $5 B$ & $\operatorname{Ar}$ & A & A & $\mathrm{H} 4$ \\
\hline MSB_348 & NGA KYWE PHYU & Ayeyarwady Division & u & u & 1 & $\operatorname{Ar}$ & A & A & ns \\
\hline MSB_352 & NGA KYWE PHYU & Ayeyarwady Division & $R L$ & u & 1 & $\operatorname{Ar}$ & A & A & $\mathrm{H} 7$ \\
\hline MSB_1114 & NGA KYWE TAUNG PYAN & Ayeyarwady Division & $\mathrm{RL}$ & u & $5 B$ & $\operatorname{Ar}$ & A & A & ns \\
\hline MSB_1799 & NGA KYWE TAUNG PYAN & Yangon Division & $\mathrm{RL}$ & u & 1 & $\mathrm{Ar}$ & $A$ & $A$ & $\mathrm{H} 2$ \\
\hline MSB_1789 & NGA KYWE YIN & Kayin State & $R L$ & u & $5 B$ & $\operatorname{Ar}$ & A & $P$ & H5 \\
\hline MSB_410 & NGA KYWE YIN & Ayeyarwady Division & $\mathrm{RL}$ & u & $5 B$ & $\mathrm{Ar}$ & $A$ & A & ns \\
\hline MSB_1871 & NGA PYA GYI & Mandalay Division & $\mathrm{RL}$ & u & $5 B$ & $\operatorname{Ar}$ & A & $P$ & $\mathrm{H} 5$ \\
\hline IRGC_33552 & PATHEIN NYUNT & Ayeyarwady delta zone & u & 5 & $5 B$ & $\mathrm{Ar}$ & A & $\mathrm{P}$ & H5 \\
\hline MSB_2579 & PAW SAN BAY KYAR & Ayeyarwady Division & $\mathrm{RL}$ & u & $5 B$ & $\mathrm{Ar}$ & A & $P$ & $\mathrm{H} 5$ \\
\hline MSB_2877 & PAW SAN BAY KYAR & Ayeyarwady Division & $\mathrm{RL}$ & u & 1 & $\operatorname{Ar}$ & u & A & $\mathrm{H} 7$ \\
\hline MSB_2925 & PAW SAN BAY KYAR & Ayeyarwady Division & $\mathrm{RL}$ & u & $5 B$ & $\mathrm{Ar}$ & u & A & ns \\
\hline MSB_3163 & PAW SAN BAY KYAR & u & $\mathrm{RL}$ & u & $5 B$ & $\operatorname{Ar}$ & u & $P$ & ns \\
\hline MSB_804 & PAW SAN BAY KYAR & Ayeyarwady Division & $\mathrm{RL}$ & u & $5 B$ & $\mathrm{Ar}$ & u & $P$ & H5 \\
\hline MSB_807 & PAW SAN BAY KYAR & Ayeyarwady Division & $\mathrm{RL}$ & u & $5 B$ & $\operatorname{Ar}$ & $A$ & $A$ & $\mathrm{H} 2$ \\
\hline MSB_1207 & PAW SAN HMWE & Ayeyarwady Division & u & u & $5 B$ & $\mathrm{Ar}$ & A & $P$ & $\mathrm{H} 5$ \\
\hline MSB_1641 & PAW SAN HMWE & Ayeyarwady Division & $\mathrm{RL}$ & u & 1 & $\mathrm{Ar}$ & A & A & ns \\
\hline MSB_2082 & PAW SAN HMWE & u & $\mathrm{RL}$ & u & 1 & $\mathrm{Ar}$ & u & A & ns \\
\hline
\end{tabular}


Table 1 List of the 147 Myanmar accessions assayed (Continued)

\begin{tabular}{|c|c|c|c|c|c|c|c|c|c|}
\hline MSB_2502 & PAW SAN HMWE & Ayeyarwady Division & $\mathrm{RL}$ & u & 1 & $\mathrm{Ar}$ & A & A & $\mathrm{H} 6$ \\
\hline MSB_2620 & PAW SAN HMWE & Ayeyarwady Division & $\mathrm{RL}$ & u & $5 B$ & $\mathrm{Ar}$ & u & $P$ & ns \\
\hline MSB_5802 & PAW SAN HMWE & u & $\mathrm{RL}$ & u & 1 & $\mathrm{Ar}$ & u & A & ns \\
\hline MSB_6973 & PAW SAN HMWE BAY KYAR & Rakhine State & $\mathrm{RL}$ & u & $5 B$ & $\mathrm{Ar}$ & u & $P$ & H5 \\
\hline MSB_7005 & PAW SAN HMWE KAUK YIN & Rakhine State & $\mathrm{RL}$ & u & $5 B$ & $\mathrm{Ar}$ & A & A & $\mathrm{H} 2$ \\
\hline MSB_2577 & PAW SAN SHWE WAR & Ayeyarwady Division & u & u & $5 B$ & $\mathrm{Ar}$ & A & A & $\mathrm{H} 2$ \\
\hline MSB_2924 & PAW SAN TAUNG PYAN HMWE & Yangon Division & u & u & $5 B$ & $\mathrm{Ar}$ & u & A & $\mathrm{H} 2$ \\
\hline MSB_1128 & PAW SAN YIN & Ayeyarwady Division & $\mathrm{RL}$ & u & $5 B$ & $\mathrm{Ar}$ & A & $P$ & H5 \\
\hline MSB_163 & SABA NET & Mandalay Division & $\mathrm{RL}$ & u & 1 & $\operatorname{Ar}$ & A & A & ns \\
\hline MSB_2261 & SABA NET & Kayah State & $\mathrm{RL}$ & u & $\mathrm{m}$ & $\operatorname{Ar}$ & u & A & $\mathrm{H} 6$ \\
\hline MSB_1915 & SABA NET KAUK YIN & Mandalay Division & 1 & u & $5 B$ & $\mathrm{Ar}$ & u & A & ns \\
\hline MSB_682 & SABANI HMWE & Tanitharyi Division & $\mathrm{RL}$ & u & 1 & $\mathrm{Ar}$ & $\mathrm{P}$ & A & $\mathrm{H} 1$ \\
\hline MSB_75 & SHWE WAR KAUK HNYIN & Yangon Division & u & u & 1 & $\mathrm{Ar}$ & A & A & $\mathrm{H} 2$ \\
\hline MSB_1628 & TAUNG PYAN HMWE & Kayin State & $\mathrm{RL}$ & u & 1 & $\mathrm{Ar}$ & A & A & $\mathrm{H} 9$ \\
\hline MSB_1621 & TAUNG PYAN SA BA NET & Bago Division & $\mathrm{RL}$ & u & $m$ & $\mathrm{Ar}$ & A & A & $\mathrm{H} 9$ \\
\hline MSB_6096 & TAUNG YAR KAUK HNYIN & Shan State & u & u & 1 & $\operatorname{Ar}$ & A & A & $\mathrm{H} 2$ \\
\hline MSB_1786 & THET NU SABA NET PYAN & Yangon Division & $\mathrm{RL}$ & u & $5 B$ & $\mathrm{Ar}$ & u & A & $\mathrm{H} 4$ \\
\hline MSB_1791 & TYAUNG PYAN YIN & Ayeyarwady Division & $\mathrm{RL}$ & u & 1 & $\operatorname{Ar}$ & u & A & $\mathrm{H} 1$ \\
\hline MSB_1792 & TYAUNG PYAN YIN & Bago Division & $\mathrm{RL}$ & u & $5 B$ & $\mathrm{Ar}$ & u & A & $\mathrm{H} 4$ \\
\hline IRGC_32293 & YANGON SABA & Southern plain zone & u & 5 & $5 B$ & $\mathrm{Ar}$ & A & $P$ & ns \\
\hline MSB_788 & YAR KAUK HNYIN & Shan State & $\mathrm{RL}$ & u & 1 & $\operatorname{Ar}$ & A & A & ns \\
\hline MSB_2528 & YWA LWE & Kachin State & $\mathrm{RU}$ & u & 1 & $\mathrm{Ar}$ & A & A & $\mathrm{H} 7$ \\
\hline MSB_311 & AUNG LAN DAW & Bago Division & $\mathrm{RL}$ & u & 1 & $\mathrm{Na}$ & A & A & ns \\
\hline IRGC_32959 & BALUGUN KAUKKYI & Ayeyarwady delta zone & u & 5 & $5 B$ & $\mathrm{Na}$ & A & A & ns \\
\hline MSB_537 & BAW GYI & Ayeyarwady Division & $\mathrm{RL}$ & u & 1 & $\mathrm{Na}$ & A & A & ns \\
\hline MSB_211 & BU DO THE & Shan State & RU & u & 1 & $\mathrm{Na}$ & A & A & ns \\
\hline MSB_769 & $\mathrm{BU} \mathrm{RO}$ & Kayin State & $\mathrm{RL}$ & u & 1 & $\mathrm{Na}$ & A & A & ns \\
\hline MSB_2587 & BU SABA & Tanitharyi Division & $R L$ & u & 1 & $\mathrm{Na}$ & A & A & $\mathrm{H} 14$ \\
\hline IRGC_6804 & D 44-1 & Southern plain zone & u & 5 & $5 B$ & $\mathrm{Na}$ & A & A & $\mathrm{H} 3$ \\
\hline MSB_635 & EPA TINE & Kayin State & $\mathrm{RL}$ & u & 1 & $\mathrm{Na}$ & A & A & ns \\
\hline MSB_2512 & KALA GYI NGA SEIN & Mon State & $R L$ & u & 1 & $\mathrm{Na}$ & A & A & ns \\
\hline MSB_498 & KAUK KYI THEE DAT & Bago Division & $\mathrm{RL}$ & u & 1 & $\mathrm{Na}$ & A & A & ns \\
\hline IRGC_33191 & KAUKKYI MEEDON & Ayeyarwady delta zone & u & 5 & 1 & $\mathrm{Na}$ & A & A & ns \\
\hline MSB_240 & KHAO KHAN NEW & Shan State & $\mathrm{RU}$ & u & 1 & $\mathrm{Na}$ & A & A & ns \\
\hline MSB_263 & KHAO LONE KHONE & Shan State & $\mathrm{RU}$ & u & 1 & $\mathrm{Na}$ & A & A & ns \\
\hline MSB_158 & KHAO MON HAN YOUNG & Kayah State & $\mathrm{RU}$ & u & 1 & $\mathrm{Na}$ & A & A & ns \\
\hline MSB_519 & KHAO NWAN & Shan State & $\mathrm{RU}$ & u & 1 & $\mathrm{Na}$ & A & A & ns \\
\hline MSB_218 & KHAO SING SAUK & Shan State & $\mathrm{RU}$ & u & 1 & $\mathrm{Na}$ & A & A & ns \\
\hline MSB_353 & KYAR GALAY & Mon State & $R L$ & u & 1 & $\mathrm{Na}$ & A & A & ns \\
\hline MSB_728 & KYAW KHAW & Kachin State & $\mathrm{RU}$ & u & 1 & $\mathrm{Na}$ & A & A & ns \\
\hline MSB_230 & KYEE MASHE & Mandalay Division & $\mathrm{RL}$ & u & 1 & $\mathrm{Na}$ & A & A & ns \\
\hline IRGC_33280 & KYEEARNI & Southern plain zone & u & 5 & $5 B$ & $\mathrm{Na}$ & A & A & ns \\
\hline IRGC_33282 & KYEEME & u & u & 5 & $5 B$ & $\mathrm{Na}$ & u & u & ns \\
\hline IRGC_33283 & KYEENI & Southern plain zone & u & 5 & $5 B$ & $\mathrm{Na}$ & A & A & ns \\
\hline IRGC_33287 & KYWEKYUT MEEDON & Ayeyarwady delta zone & u & 5 & $\mathrm{~m}$ & $\mathrm{Na}$ & A & A & ns \\
\hline
\end{tabular}


Table 1 List of the 147 Myanmar accessions assayed (Continued)

\begin{tabular}{|c|c|c|c|c|c|c|c|c|c|}
\hline IRGC_33301 & LAWTHAWPHINME (E62-10) & Southern coastal zone & u & 5 & $5 B$ & $\mathrm{Na}$ & A & A & ns \\
\hline IRGC_33304 & LEIKKALAY MEEDON & Southern plain zone & u & 5 & $5 B$ & $\mathrm{Na}$ & A & A & $\mathrm{H} 2$ \\
\hline MSB_2560 & LET TAW YWE BAW & Mon State & RL & u & 1 & $\mathrm{Na}$ & A & A & ns \\
\hline MSB_577 & LONE PHYU & Mon State & u & u & 1 & $\mathrm{Na}$ & A & A & ns \\
\hline MSB_285 & MA PO LAY & Ayeyarwady Division & $\mathrm{RL}$ & u & 1 & $\mathrm{Na}$ & A & A & ns \\
\hline IRGC_33373 & MAYZI & Western coastal zone & u & 5 & $\mathrm{~m}$ & $\mathrm{Na}$ & A & A & ns \\
\hline IRGC_33379 & MEEDON YIN & Semi-arid zone & u & 5 & $5 B$ & $\mathrm{Na}$ & A & A & ns \\
\hline IRGC_33380 & MEEDON YOYO & Ayeyarwady delta zone & u & 5 & 1 & $\mathrm{Na}$ & A & A & ns \\
\hline MSB_109 & NAGA NEW & Rakhine State & $\mathrm{RL}$ & u & 1 & $\mathrm{Na}$ & A & A & ns \\
\hline IRGC_58152 & NGA KYWE GYI & Western coastal zone & u & 5 & $\mathrm{~m}$ & $\mathrm{Na}$ & A & A & $\mathrm{H} 6$ \\
\hline MSB_404 & NGA YUN WAR & Bago Division & $\mathrm{RL}$ & u & 1 & $\mathrm{Na}$ & A & A & ns \\
\hline IRGC_33466 & NGAKYEIN THEE SHAY & Western coastal zone & u & 5 & 1 & $\mathrm{Na}$ & A & A & ns \\
\hline IRGC_33467 & NGAKYWE & Ayeyarwady delta zone & u & 5 & $\mathrm{~m}$ & $\mathrm{Na}$ & A & A & ns \\
\hline IRGC_33468 & NGAKYWE & Ayeyarwady delta zone & u & 5 & m & $\mathrm{Na}$ & A & A & ns \\
\hline IRGC_33469 & NGAKYWE & Ayeyarwady delta zone & u & 5 & $5 B$ & $\mathrm{Na}$ & A & A & ns \\
\hline IRGC_11142 & NGAKYWE TAUNG PYAN & Ayeyarwady delta zone & u & 5 & $5 B$ & $\mathrm{Na}$ & A & A & ns \\
\hline IRGC_33478 & NGA-KYWE YIN & Eastern plateau & u & 5 & $5 B$ & $\mathrm{Na}$ & A & A & $\mathrm{H} 2$ \\
\hline IRGC_58154 & NGAYA PAUK & Western coastal zone & u & 5 & $\mathrm{~m}$ & $\mathrm{Na}$ & A & A & ns \\
\hline IRGC_33521 & NGAYUN TAUNGPYAN & Southern plain zone & u & 5 & 1 & $\mathrm{Na}$ & A & A & ns \\
\hline IRGC_58172 & PATEEPU/OO PAUK & Southern plain zone & u & 5 & $5 \mathrm{~A}$ & $\mathrm{Na}$ & A & A & ns \\
\hline IRGC_33551 & PATHEIN NGAKYWE & Ayeyarwady delta zone & u & 5 & $5 B$ & $\mathrm{Na}$ & A & A & ns \\
\hline IRGC_33590 & POKEKYI & Southern plain zone & u & 5 & $5 B$ & $\mathrm{Na}$ & A & A & ns \\
\hline IRGC_33596 & PYAPON THEEDAT & Ayeyarwady delta zone & u & 5 & $\mathrm{~m}$ & $\mathrm{Na}$ & A & A & ns \\
\hline IRGC_33605 & SABANET KAUKYIN & Semi-arid zone & u & 5 & $5 B$ & $\mathrm{Na}$ & A & A & ns \\
\hline IRGC_58191 & SAN KAR YAN THAE & Southern plain zone & u & 5 & 6 & $\mathrm{Na}$ & A & A & $\mathrm{H} 2$ \\
\hline MSB_234 & SAN SHWE NI & Bago Division & $\mathrm{RL}$ & u & 1 & $\mathrm{Na}$ & A & A & ns \\
\hline MSB_66 & SHWE NI TWAT SUN & Yangon Division & $\mathrm{RL}$ & u & 1 & $\mathrm{Na}$ & A & A & ns \\
\hline IRGC_33668 & SHWEDINGA & Semi-arid zone & u & 5 & $5 B$ & $\mathrm{Na}$ & A & A & ns \\
\hline IRGC_33704 & SHWEWA & Ayeyarwady delta zone & u & 5 & $5 B$ & $\mathrm{Na}$ & A & A & ns \\
\hline IRGC_33708 & SHWEWA HNAN & Ayeyarwady delta zone & u & 5 & $5 B$ & $\mathrm{Na}$ & A & A & ns \\
\hline IRGC_33709 & SHWEWA KAMAKYI & Ayeyarwady delta zone & u & 5 & $5 B$ & $\mathrm{Na}$ & A & A & ns \\
\hline IRGC_33706 & SHWEWAGYI & Ayeyarwady delta zone & u & 5 & 1 & $\mathrm{Na}$ & A & A & ns \\
\hline IRGC_33712 & SHWEWAYIN & Southern plain zone & u & 5 & 1 & $\mathrm{Na}$ & A & A & ns \\
\hline MSB_217 & TADAUNG PO & Ayeyarwady Division & D & u & 1 & $\mathrm{Na}$ & A & A & ns \\
\hline MSB_1403 & TAR SAING & Kachin State & $\mathrm{RU}$ & u & 1 & $\mathrm{Na}$ & A & A & ns \\
\hline IRGC_33745 & TAUNGDI & Southern plain zone & u & 5 & $5 B$ & $\mathrm{Na}$ & A & A & ns \\
\hline IRGC_33747 & TAUNGGYI KAUKKYI & Eastern plateau zone & u & 5 & $5 B$ & $\mathrm{Na}$ & A & A & ns \\
\hline IRGC_33752 & TAUNGPYAN & Ayeyarwady delta zone & u & 5 & $5 B$ & $\mathrm{Na}$ & A & A & ns \\
\hline IRGC_33755 & TAUNGPYAN KAUKNGE & Ayeyarwady delta zone & u & 5 & $5 B$ & $\mathrm{Na}$ & A & A & ns \\
\hline IRGC_33757 & TAUNGPYANYIN & Southern plain zone & u & 5 & $5 B$ & $\mathrm{Na}$ & A & A & ns \\
\hline IRGC_33749 & TAUNGTI & Southern plain zone & u & 5 & $5 B$ & $\mathrm{Na}$ & A & A & ns \\
\hline IRGC_33773 & THATNU SABANET & Southern plain zone & u & 5 & $5 B$ & $\mathrm{Na}$ & A & A & ns \\
\hline MSB_984 & THEE DAT PYA PON & Ayeyarwady Division & $\mathrm{RL}$ & u & 1 & $\mathrm{Na}$ & A & A & ns \\
\hline MSB_67 & THEE HTAT NGA SEIN & Yangon Division & $\mathrm{RL}$ & u & 1 & $\mathrm{Na}$ & A & A & $\mathrm{H} 6$ \\
\hline MSB_647 & THEE HTAT PIN KHINE & Sagaing Division & $\mathrm{RL}$ & u & $5 \mathrm{~A}$ & $\mathrm{Na}$ & A & A & $\mathrm{H} 2$ \\
\hline
\end{tabular}


Table 1 List of the 147 Myanmar accessions assayed (Continued)

\begin{tabular}{|c|c|c|c|c|c|c|c|c|c|}
\hline IRGC_33791 & THIT PIN & Western coastal zone & u & 5 & $\mathrm{~m}$ & $\mathrm{Na}$ & A & A & ns \\
\hline MSB_65 & THONE HNAN PWA & Yangon Division & $\mathrm{RL}$ & u & 1 & $\mathrm{Na}$ & A & A & ns \\
\hline IRGC_33805 & THONESATOE NGAKWE & Southern plain zone & u & 5 & $5 B$ & $\mathrm{Na}$ & A & A & ns \\
\hline IRGC_33802 & THONSATOE & Semi-arid zone & u & 5 & 2 & $\mathrm{Na}$ & A & A & ns \\
\hline MSB_113 & TIN TANE & Kachin State & $\mathrm{RL}$ & u & 1 & $\mathrm{Na}$ & A & A & ns \\
\hline MSB_925 & WA KHE MA HNAN KAR & Ayeyarwady Division & $\mathrm{D}$ & u & 1 & $\mathrm{Na}$ & A & A & ns \\
\hline IRGC_33835 & WUNKYAW & Southern plain zone & u & 5 & 1 & $\mathrm{Na}$ & A & A & ns \\
\hline IRGC_58247 & YAT SAUK SABA & Eastern plateau zone & u & 5 & $\mathrm{~m}$ & $\mathrm{Na}$ & A & A & ns \\
\hline MSB_91 & YAY MA NAING MIN THAR GYI & Yangon Division & $\mathrm{D}$ & u & 1 & $\mathrm{Na}$ & A & A & $\mathrm{H} 7$ \\
\hline MSB_33 & ZAWTIKA GYI & Yangon Division & $\mathrm{RL}$ & u & 1 & $\mathrm{Na}$ & A & A & ns \\
\hline MSB_233 & ZEIN YIN & Bago Division & $\mathrm{RL}$ & u & 1 & $\mathrm{Na}$ & A & A & ns \\
\hline IRGC_33192 & KAUKKYISAW & Southern coastal zone & u & 5 & $5 B$ & u & A & A & $\mathrm{H} 6$ \\
\hline IRGC_5946 & NGAKYWE D 25-4 & Southern plain zone & u & 5 & $\mathrm{~m}$ & u & A & A & $\mathrm{H} 6$ \\
\hline IRGC_33888 & YELAIK MEEDON & u & u & 5 & $5 B$ & u & A & A & $\mathrm{H} 2$ \\
\hline
\end{tabular}

$R L$ rainfed lowland, $R U$ rainfed upland, $D$ deepwater, I irrigated, $u$ unknown, EG Enzymatic Group, $m=$ admixed; $A r$ aromatic, Na non-aromatic; Genotype: 8 bp del. $=8$ bp deletion in exon 7 in comparison with Nipponbare sequence; 3 bp ins. = 3 bp insertion in exon 13 in comparison with Nipponbare sequence; $A$ absent, $P$ present, Haplotype: $n s$ not sequenced.

for which the information was not available were labeled "unknown" (u).

\section{Genotyping}

DNA was extracted from one plant per accession using the MATAB method (Risterucci et al. 2000). A set of 19 simple sequence repeat (SSR) markers distributed on the 12 chromosomes was genotyped on the 147 Myanmar accessions and the 31 reference set accessions from group 5. The SSR markers are listed in Table 2. The other 49 reference set accessions had already been genotyped with the same markers (Courtois et al. unpublished results). The genotyping was performed according to the protocol of Roy et al. (1996) implemented with the automated infrared fluorescence technology of LICOR 3200 sequencers (Li-COR, Lincoln, Nebraska, USA) at CIRAD genotyping and robotics platform, Montpellier, France. Primer sequences were retrieved from the Gramene database (www.gramene.org). For a given SSR locus, the forward primer was designed with a 5'-end M13 tail (5'-CACGACGTTGTAAAACGAC-3'). The polymerase chain reaction (PCR) amplifications were performed in a Eppendorf Mastercycler (Eppendorf, Hamburg, Germany) on $25 \mathrm{ng}$ of DNA in a final volume of $10 \mu \mathrm{l}$ of buffer $(10 \mathrm{mM}$ Tris- $\mathrm{HCl}(\mathrm{pH} 8), 100 \mathrm{mM} \mathrm{KCl}$, and $0.5 \mathrm{mM} \mathrm{MgCl} 2$ ) containing $0.08 \mu \mathrm{M}$ of the M13tailed primer, $0.1 \mu \mathrm{M}$ of the other primer, $200 \mu \mathrm{M}$ of dNTP, 1 U of Taq DNA polymerase (Invitrogen, Carlsbad, California, USA), and $0.1 \mu \mathrm{M}$ of M13 primer-fluorescent dye IR700 or IR800 (Eurofins-MWG, Ebersberg, Germany). The PCR programme included an initial denaturation cycle at $95^{\circ} \mathrm{C}$ for $4 \mathrm{~min}, 35$ cycles at $94^{\circ} \mathrm{C}$ for $1 \mathrm{~min}$, $\mathrm{Tm}$ for $1 \mathrm{~min}$, and $72^{\circ} \mathrm{C}$ for $1 \mathrm{~min}$, and a final elongation step at $72^{\circ} \mathrm{C}$ for $8 \mathrm{~min}$. IR700 or IR800labeled PCR products were diluted 7 -fold and 5-fold respectively, subjected to electrophoresis in a $6.5 \%$ polyacrylamide gel and then sized by the infra red fluorescence scanning system of the sequencer. Allele calling was performed twice by two different persons based on five DNA pools of known allele size included in each gel and used as standards.

The 178 accessions were also genotyped with two other primer pairs, the first one to detect an $8 \mathrm{bp}$ deletion and the second one to detect a $3 \mathrm{bp}$ insertion in the coding sequence of the $B A D H 2$ gene. The sequences of the two primer pairs are listed in Additional file 1: Table S2.

\section{Statistical analyses}

The allele number, allele frequencies and polymorphism information content (PIC) of each marker were computed using PowerMarker version 3.25 (Liu and Muse 2005).

We used both a distance-based and a model-based approach to assess the genetic structure of the whole population (Myanmar accessions and the reference set). A dissimilarity matrix was computed using a shared allele index with DarWin software (Perrier and Jacquemoud-Collet 2006). An unweighted neighborjoining $(\mathrm{NJ})$ tree was built based on this dissimilarity matrix. The number of sub-populations, K, in the population was assessed in parallel using the software Structure v2.3 (Pritchard et al. 2000). The program was run with the following parameters: haploid data, possibility of admixture and correlated allelic frequencies. A run was composed of 100,000 burn-ins followed by 100,000 
Table 2 Characteristics of the 19 SSR loci including their repeat motif, the number of alleles per locus, and PIC value in the two rice collections (Myanmar and reference set)

\begin{tabular}{|c|c|c|c|c|c|c|c|c|c|c|}
\hline \multirow[t]{2}{*}{ Marker } & \multirow[t]{2}{*}{ Chr. } & \multirow[t]{2}{*}{ SSR motif } & \multicolumn{2}{|c|}{ Reference set accessions ${ }^{1}$} & \multicolumn{2}{|c|}{ Myanmar collection ${ }^{2}$} & \multicolumn{2}{|c|}{ Reference set group $5^{3}$} & \multicolumn{2}{|c|}{ Myanmar group $5^{4}$} \\
\hline & & & No of alleles & PIC & No of alleles & PIC & No of alleles & PIC & No of alleles & PIC \\
\hline RM1 & 1 & $(G A) 26$ & 13 & 0.82 & 16 & 0.73 & 5 & 0.50 & 9 & 0.48 \\
\hline RM5 & 1 & $(G A) 14$ & 11 & 0.85 & 9 & 0.82 & 8 & 0.72 & 9 & 0.83 \\
\hline RM11 & 7 & $(\mathrm{GA}) 17$ & 10 & 0.78 & 9 & 0.67 & 4 & 0.36 & 7 & 0.37 \\
\hline RM25 & 8 & $(\mathrm{GA}) 18$ & 11 & 0.69 & 10 & 0.75 & 6 & 0.45 & 6 & 0.64 \\
\hline RM44 & 8 & $(G A) 16$ & 11 & 0.72 & 5 & 0.67 & 3 & 0.42 & 5 & 0.53 \\
\hline RM124 & 4 & (TC)10 & 4 & 0.56 & 3 & 0.42 & 4 & 0.60 & 3 & 0.30 \\
\hline RM154 & 2 & $(G A) 21$ & 15 & 0.89 & 12 & 0.85 & 9 & 0.74 & 10 & 0.82 \\
\hline RM215 & 9 & $(C T) 16$ & 7 & 0.66 & 7 & 0.52 & 4 & 0.50 & 6 & 0.45 \\
\hline RM237 & 1 & (CT)18 & 8 & 0.79 & 11 & 0.60 & 5 & 0.60 & 5 & 0.32 \\
\hline RM271 & 10 & (GA)15 & 7 & 0.69 & 8 & 0.53 & 3 & 0.37 & 7 & 0.33 \\
\hline RM287 & 11 & $(G A) 21$ & 11 & 0.61 & 12 & 0.70 & 4 & 0.23 & 9 & 0.60 \\
\hline RM316 & 9 & Complex & 9 & 0.73 & 7 & 0.30 & 7 & 0.58 & 6 & 0.22 \\
\hline RM338 & 3 & $(\mathrm{CTT}) 6$ & 3 & 0.40 & 2 & 0.24 & 2 & 0.17 & 2 & 0.36 \\
\hline RM431 & 1 & $(\mathrm{AG}) 16$ & 10 & 0.75 & 9 & 0.67 & 5 & 0.47 & 7 & 0.62 \\
\hline RM447 & 8 & $(\mathrm{CTT}) 8$ & 8 & 0.65 & 4 & 0.48 & 4 & 0.49 & 4 & 0.39 \\
\hline RM474 & 10 & (AT)13 & 14 & 0.87 & 12 & 0.71 & 6 & 0.67 & 7 & 0.55 \\
\hline RM510 & 6 & (GA)15 & 7 & 0.58 & 6 & 0.47 & 3 & 0.30 & 4 & 0.39 \\
\hline RM538 & 5 & $(G A) 14$ & 11 & 0.69 & 11 & 0.68 & 6 & 0.48 & 6 & 0.41 \\
\hline RM1227 & 12 & $(\mathrm{AG}) 15$ & 8 & 0.77 & 6 & 0.72 & 7 & 0.74 & 6 & 0.67 \\
\hline Total & & & 178 & & 159 & & 95 & & 118 & \\
\hline Average & & & 9.3 & 0.71 & 8.4 & 0.61 & 5.0 & 0.49 & 6.2 & 0.49 \\
\hline
\end{tabular}

${ }^{1} 80$ accessions; ${ }^{2} 147$ accessions; ${ }^{3} 31$ accessions; ${ }^{4} 51$ accessions.

iterations. We ran 10 runs for each value of $\mathrm{K}$, with $\mathrm{K}$ varying from 1 to 10 . For each run, the percentages of admixture in the $\mathrm{K}$ sub-populations of all accessions were computed. An accession was discretely classified in a sub-population when the admixture percentage of the accession for the sub-population concerned was above $80 \%$. Otherwise it was classified as admixed (m). To determine the most likely $\mathrm{K}$ value, we also used the criteria proposed by Evanno et al. (2005) related to the first and second order rates of change of the likelihood function with respect to $K$.

We used XLSTAT tree classification tools (Breiman et al. 1984) under Excel (http://www.xlstat.com/) to determine which markers or marker combinations best distinguished sub-populations.

The hierarchical distribution of the molecular variance within and between the sub-populations defined by Structure was assessed by analysis of molecular variance (AMOVA) with Arlequin (Excoffier et al. 2006). To evaluate the genetic differentiation between these populations, pair-wise $\mathrm{F}_{\mathrm{ST}}$ (Wright 1978) were computed with the same software, using 1000 permutations to determine their significance.

\section{Sequencing}

We sequenced the $B A D H 2$ gene (gene Os08g32870 retrieved from Gramene; position in MSU v6 chromosome 8: 20,377,081 to 20,383,348 bp) in 91 accessions: 50 aromatic, 7 non-aromatic and 3 unknowns from the Myanmar collection, and 17 aromatic, 5 non-aromatic including Nipponbare, and 9 unknowns from the reference set (Table 1). The 12 primer pairs covering the whole $B A D H 2$ gene listed in Additional file 1: Table S2 came from Vanavichit et al. (2008), Kovach et al. (2009) or Khin et al. (2012). Amplification products were purified and sequenced at GATC, Germany. The sequences, except that of Nipponbare, were deposited in the EMBLGenbank database under the accession numbers [GenBank:JQ308346 to JQ308435].

Sequence quality control, alignment and nucleotide polymorphism detection were performed using Codon Code Aligner v1.6.3 (http://www.codoncode.com/index.htm) with minimum Phred scores set at 20. Polymorphism sites were numbered starting with position 1 for the A of the ATG of the first exon (position in MSU v6: 20,377,257) based on the annotation of Chen et al. (2008). Haplotypes were manually determined. Haplotype networks, representing 
unique alleles separated by mutational steps, were constructed with NETWORK v4.5 (http://www.fluxus-technology.com/sharenet.htm) using the median-joining method (Bandelt et al. 1999), with equal weight for all sites and an eta-parameter of 0 . Both single nucleotide polymorphism (SNP) and insertions/deletions (Indels) were used, with the Indels coded in biallelic form as SNPs.

\section{Results}

\section{Genotyping}

A total of 147 varieties from Myanmar and 80 varieties from the reference set were genotyped with 19 markers. The rate of missing data was $2.4 \%$. The percentage of heterozygosity was $1.4 \%$. The PIC of each marker in the different sets is listed in Table 2.

The number of alleles per marker and the PIC were generally slightly lower in the Myanmar collection than in the reference set. Focusing on group 5 accessions, differences between the two sets were also observed from marker to marker but the Myanmar collection was globally as diverse as the reference set.

We built an NJ tree and analyzed it using the accessions with known enzymatic grouping as references (Additional file 1: Figure S1). A clear structure was revealed with one cluster of isozyme group 1 accessions, one cluster of isozyme group 2 accessions, one cluster of isozyme group 6 accessions, two clusters of isozyme group 5 accessions, and a few intermediates. The first cluster of isozyme group 5 accessions that we called $5 \mathrm{~A}$ was mainly composed of varieties from South Asia (India, Nepal, Bhutan, and Pakistan), Iran and Madagascar, and one variety from Myanmar (Kyet Paung), and the second cluster that we called $5 \mathrm{~B}$ was strictly composed of varieties from Myanmar. A few accessions among those said to belong to the Myanmar enzymatic group 5 did not cluster with the expected group: eight accessions in group 5 (Kaukkyi Meedon, Ngakyein Thee Shay, Ngakywe (IRGC 33468), Ngayun Taungpyan, Shwewagyi, Shewewayin, Wunkyaw, Meedon Yoyo) clustered with group 1 (as did two accessions in reference set group 5, T26 and Chote Dhan), two accessions clustered with group 2 (Thonsatoe, Yat Sauk Saba), one with group 6 (San Kar Yan Thae), and three additional accessions (Ngakywe D25-4, Nga Kywe Gyi, Ngakywe (IRGC 33467)) were intermediates between the groups. The Myanmar accessions for which the isozyme group was unknown, clustered massively with either group 1 (61 accessions) or group 5B (32 accessions); only two of them clustered with group 5A (Namathalay and Thee Htat Pin Khine), and one was located with the intermediates (Paw San Hwme (MSB 2923)).

Based on Structure results and Evanno's criteria (Additional file 1: Figure S2), the most likely number of sub-populations was five. We analyzed the results again based on the isozyme-based organization of the reference set. The five sub-populations detected corresponded to group 1, group 2, group 5A, group $5 \mathrm{~B}$ and group 6 (Figure 1). The projection of Structure assignation for $\mathrm{K}=5$ on the $\mathrm{NJ}$ tree was in excellent agreement with the clusters identified, including for those genotypes from enzymatic group 5 which had appeared in an unexpected NJ tree cluster. Seventeen varieties (7.5\%) were admixed.

Hierarchical analysis of molecular variance revealed a highly significant genetic differentiation among the five sub-populations with $45 \%$ of the variance due to differences among sub-populations and 55\% due to difference within sub-populations. The pair-wise $\mathrm{F}_{\mathrm{ST}}$ varied between 0.31 and 0.63 , indicating high differentiation between sub-populations. Sub-population 5B showed a high and similar level of differentiation from group 1 (FST of 0.52), group $6(0.50)$ and from the 5A subpopulation (0.51) and an even higher level from group 2 (0.63). Sub-population 5A had moderate but similar levels of differentiation as group 1 (FST of 0.36 ) group 2 $(0.34)$ and group $6(0.31)$. These high $\mathrm{F}_{\mathrm{ST}}$ were consistent with the strong structure revealed by the NJ tree.

The distinction between two sub-populations among accessions belonging to isozyme group 5 was unexpected. We used classification and regression tree methods (Breiman et al. 1984) to determine which markers best distinguished sub-population 5A from $5 \mathrm{~B}$. RM11, located on chromosome 7, enabled to a posteriori correctly predict $100 \%$ of the a priori grouping, with allele 140 present only in sub-population 5B and alleles 142,144 and 148 present only in sub-population 5A.

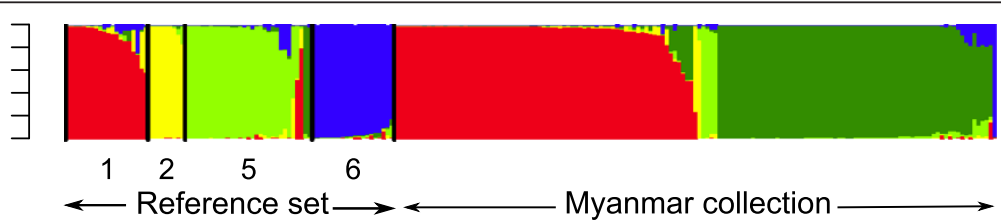

Figure $1 \mathrm{Graph}$ of estimated membership fraction for $\mathrm{K}=\mathbf{5}$ (run with the highest likelihood). The first part of the graph represents the reference set with a vertical black bar separating the enzymatic groups. 
Table 3 Position of the 36 polymorphisms detected in the 91 accessions sequenced, after eliminating 26 singletons and one SSR, and structure of the 15 haplotypes observed

\begin{tabular}{|c|c|c|c|c|c|c|c|c|c|c|c|c|c|c|c|c|c|c|c|c|}
\hline Pos. & Zone & $P$ & Nature & Freq. & Cons & $\mathrm{H} 1$ & $\mathrm{H} 2$ & $\mathrm{H} 3$ & $\mathrm{H} 4$ & H5 & $\mathrm{H} 6$ & $\mathrm{H7}$ & $\mathrm{H} 8$ & $\mathrm{H} 9$ & $\mathrm{H} 10$ & $\mathrm{H} 11$ & $\mathrm{H} 12$ & $\mathrm{H} 13$ & $\mathrm{H} 14$ & $\mathrm{H} 15$ \\
\hline 695 & 12 & snp & $\mathrm{nc}$ & 2.2 & $C$ & $C$ & C & C & $C$ & C & C & $C$ & C & $C$ & $C$ & $C$ & $\mathrm{G}$ & $G$ & $C$ & C \\
\hline 825 & 12 & snp & $\mathrm{nc}$ & 7.7 & C & $C$ & C & C & C & C & T & $C$ & C & C & C & C & C & C & C & C \\
\hline 829 & 12 & snp & $\mathrm{nc}$ & 3.3 & $\mathrm{~T}$ & $\mathrm{~T}$ & T & $\mathrm{T}$ & $\mathrm{T}$ & $\mathrm{T}$ & $\mathrm{T}$ & $\mathrm{T}$ & T & T & $\mathrm{T}$ & T & $C$ & $C$ & C & $\mathrm{T}$ \\
\hline 839 & 12 & indel & $\mathrm{nc}$ & 29.7 & 0 & 0 & 0 & 0 & 0 & 0 & 2 & 2 & 2 & 2 & 2 & 2 & 2 & 2 & 2 & 2 \\
\hline 876 & 12 & snp & $\mathrm{nc}$ & 2.2 & A & $A$ & A & A & A & A & A & A & G & A & A & A & A & A & A & A \\
\hline 915 & 12 & snp & $\mathrm{nc}$ & 25.3 & C & C & C & C & C & C & $\mathrm{T}$ & $\mathrm{T}$ & T & $\mathrm{T}$ & $\mathrm{T}$ & $\mathrm{T}$ & C & C & C & C \\
\hline 918 & 12 & snp & $\mathrm{nc}$ & 2.2 & T & T & T & T & T & T & $\mathrm{T}$ & $\mathrm{T}$ & C & T & $\mathrm{T}$ & $\mathrm{T}$ & $\mathrm{T}$ & $\mathrm{T}$ & T & $\mathrm{T}$ \\
\hline 1082 & 12 & snp & $\mathrm{nc}$ & 21.9 & $\mathrm{~T}$ & T & $\mathrm{T}$ & $T$ & $\mathrm{~T}$ & $\mathrm{~T}$ & C & C & C & $\mathrm{T}$ & $\mathrm{T}$ & T & $\mathrm{T}$ & $\mathrm{T}$ & $\mathrm{T}$ & $\mathrm{T}$ \\
\hline 1112 & 12 & snp & $\mathrm{nc}$ & 25.3 & A & A & A & A & A & A & $\mathrm{T}$ & $\mathrm{T}$ & T & T & $\mathrm{T}$ & $\mathrm{T}$ & A & A & A & A \\
\hline 1113 & 12 & indel & $\mathrm{nc}$ & 25.3 & 3 & 3 & 3 & 3 & 3 & 3 & 0 & 0 & 0 & 0 & 0 & 0 & 3 & 3 & 3 & 3 \\
\hline 1316 & 12 & snp & $\mathrm{nc}$ & 7.7 & G & G & G & G & G & G & A & G & G & G & G & G & G & G & G & G \\
\hline 1340 & 12 & snp & $\mathrm{nc}$ & 23.1 & C & C & C & C & C & C & G & $\mathrm{G}$ & G & $\mathrm{G}$ & C & C & C & C & C & C \\
\hline 1819 & 14 & snp & $\mathrm{nc}$ & 25.3 & $\mathrm{~T}$ & $\mathrm{~T}$ & $\mathrm{~T}$ & $\mathrm{~T}$ & $\mathrm{~T}$ & $\mathrm{~T}$ & A & $A$ & A & A & A & A & $\mathrm{T}$ & $\mathrm{T}$ & $\mathrm{T}$ & $\mathrm{T}$ \\
\hline 2142 & 14 & snp & $\mathrm{nc}$ & 26.4 & $\mathrm{~T}$ & $\mathrm{~T}$ & $\mathrm{~T}$ & $\mathrm{~T}$ & $\mathrm{~T}$ & $\mathrm{~T}$ & A & $A$ & A & A & $A$ & $A$ & $\mathrm{~T}$ & $\mathrm{~T}$ & $\mathrm{~T}$ & $A$ \\
\hline 2144 & 14 & snp & $\mathrm{nc}$ & 8.8 & $\mathrm{~T}$ & $\mathrm{~T}$ & $\mathrm{~T}$ & $\mathrm{~T}$ & $\mathrm{~T}$ & $\mathrm{~T}$ & A & $\mathrm{T}$ & $\mathrm{T}$ & $\mathrm{T}$ & $\mathrm{T}$ & A & $\mathrm{T}$ & $\mathrm{T}$ & $\mathrm{T}$ & $\mathrm{T}$ \\
\hline 2205 & 14 & snp & $\mathrm{nc}$ & 26.4 & A & A & A & A & A & A & G & G & G & G & G & G & G & A & A & A \\
\hline 2219 & 14 & snp & $\mathrm{nc}$ & 25.3 & $\mathrm{G}$ & G & G & G & G & G & A & $A$ & A & $A$ & $A$ & $A$ & G & G & $\mathrm{G}$ & $\mathrm{G}$ \\
\hline 2889 & E7 & snp & c & 25.3 & A & $\mathrm{T}$ & A & A & A & A & A & $A$ & A & A & A & A & A & A & A & A \\
\hline 2891 & E7 & snp & c & 25.3 & A & $\mathrm{T}$ & A & A & A & A & A & A & A & A & $A$ & $A$ & A & A & A & A \\
\hline 2893 & E7 & snp & c & 24.2 & A & G & A & A & A & A & A & A & A & A & A & A & A & A & A & A \\
\hline 2894 & E7 & indel & c & 25.3 & 8 & 0 & 8 & 8 & 8 & 8 & 8 & 8 & 8 & 8 & 8 & 8 & 8 & 8 & 8 & 8 \\
\hline 3003 & 17 & indel & $\mathrm{nc}$ & 7.7 & $\mathrm{~T}$ & $\mathrm{~T}$ & $\mathrm{~T}$ & $\mathrm{~T}$ & $\mathrm{~T}$ & $\mathrm{~T}$ & 0 & $\mathrm{~T}$ & $\mathrm{~T}$ & $\mathrm{~T}$ & $\mathrm{~T}$ & $\mathrm{~T}$ & $\mathrm{~T}$ & $\mathrm{~T}$ & $\mathrm{~T}$ & $\mathrm{~T}$ \\
\hline 3031 & 17 & snp & $\mathrm{nc}$ & 3.3 & G & G & G & G & G & G & G & $\mathrm{G}$ & G & G & G & G & $\mathrm{T}$ & $\mathrm{T}$ & $\mathrm{T}$ & G \\
\hline 3219 & 18 & snp & $\mathrm{nc}$ & 12.1 & $C$ & C & C & C & $\mathrm{T}$ & C & C & $C$ & C & $C$ & $C$ & C & $\mathrm{T}$ & $\mathrm{T}$ & C & $C$ \\
\hline 3220 & 18 & snp & $\mathrm{nc}$ & 25.3 & G & G & G & G & G & G & A & A & A & A & A & A & G & G & G & G \\
\hline 3372 & 18 & snp & $\mathrm{nc}$ & 25.3 & $C$ & C & C & C & C & C & G & G & G & G & G & G & $C$ & C & C & $C$ \\
\hline 3467 & 18 & snp & $\mathrm{nc}$ & 25.3 & T & $\mathrm{T}$ & T & T & T & T & C & $C$ & C & C & C & $C$ & $\mathrm{~T}$ & $\mathrm{~T}$ & T & $\mathrm{T}$ \\
\hline 3988 & 19 & snp & $\mathrm{nc}$ & 2.2 & T & $\mathrm{T}$ & T & T & $\mathrm{T}$ & $\mathrm{T}$ & $\mathrm{T}$ & $\mathrm{T}$ & T & T & G & G & $\mathrm{T}$ & $\mathrm{T}$ & $\mathrm{T}$ & $\mathrm{T}$ \\
\hline 4423 & 110 & snp & $\mathrm{nc}$ & 2.2 & C & C & C & C & C & C & C & $C$ & C & C & G & G & $C$ & $C$ & C & $C$ \\
\hline 4452 & 110 & snp & $\mathrm{nc}$ & 2.2 & A & A & A & A & A & A & A & A & A & A & A & A & G & G & A & A \\
\hline 5233 & E13 & indel & c & 14.3 & 0 & 0 & 0 & 0 & 0 & 3 & 0 & 0 & 0 & 0 & 0 & 0 & 0 & 0 & 0 & 0 \\
\hline 5491 & 113 & snp & $\mathrm{nc}$ & 2.2 & A & A & A & A & A & A & A & A & T & A & A & A & A & A & A & A \\
\hline 5531 & 113 & snp & $\mathrm{nc}$ & 29.7 & G & G & G & G & G & G & A & A & A & A & A & A & A & A & A & A \\
\hline 5688 & 114 & snp & $\mathrm{nc}$ & 4.4 & A & A & A & G & A & A & A & A & A & A & A & A & A & A & A & A \\
\hline 6049 & 3'UTR & snp & $\mathrm{nc}$ & 3.3 & $\mathrm{~T}$ & $\mathrm{~T}$ & $\mathrm{~T}$ & T & $\mathrm{T}$ & $\mathrm{T}$ & T & $\mathrm{T}$ & $\mathrm{T}$ & $\mathrm{T}$ & A & $\mathrm{T}$ & $\mathrm{T}$ & A & A & $\mathrm{T}$ \\
\hline 6086 & 3'UTR & indel & $\mathrm{nc}$ & 24.2 & 43 & 43 & 43 & 43 & 43 & 43 & 0 & 0 & 0 & 0 & 43 & 43 & 0 & 43 & 43 & 43 \\
\hline Aroma & & & & & & $\mathrm{Ar}$ & M & M & M & $\mathrm{Ar}$ & M & M & $\mathrm{Ar}$ & $\mathrm{Ar}$ & $\mathrm{Ar}$ & $\mathrm{Na}$ & $\mathrm{Ar}$ & $\mathrm{Ar}$ & $\mathrm{Na}$ & $\mathrm{Na}$ \\
\hline No acc. & & & & & & 23 & 15 & 4 & 9 & 13 & 7 & 10 & 2 & 2 & 1 & 1 & 1 & 1 & 1 & 1 \\
\hline Myanmar & & & & & & 6 & 13 & 2 & 6 & 13 & 7 & 7 & 0 & 2 & 1 & 0 & 1 & 1 & 1 & 0 \\
\hline
\end{tabular}

Pos. = position of the polymorphism (position 1 for the A of the ATG of the first exon corresponding to position 20,377,257 in MSU v6). Indels of more than one bp: site 839: $2=\Pi$; site 1113: $3=\Pi$ A ; site 2894: $8=$ ATTATGGC; site 5233: $3=\Pi$ A; site 6086: $43=$ GTCTCTCCGTATCGGCTTGTGGTGTTCAACCTTAAGACC.

Zone: $\mathrm{I}=$ intron; $\mathrm{E}=$ exon; Nature: $\mathrm{nc}=$ non coding; $\mathrm{c}=$ coding; $\mathrm{Ar}=$ aromatic; $\mathrm{Na}=$ non-aromatic; $\mathrm{M}=$ some accessions aromatic and other accessions non aromatic. Cons $=$ consensus sequence.

No acc. $=$ number of accessions carrying the haplotype among the 91 sequenced; Myanmar = number of accessions from Myanmar carrying the haplotype among the 60 sequenced.

Correspondence with the haplotypes from Kovach et al. (2009): $\mathrm{H} 2=$ wild type; $\mathrm{H} 1=$ badh2.1; $\mathrm{H} 5=$ badh2.8; $\mathrm{H} 15=$ Nipponbare haplotype. 
RM510 located on chromosome 6, had the same capacity with alleles 141 and 143, which were present only in sub-population 5B, and with alleles 131 and 139, which were present only in sub-population $5 \mathrm{~A}$. The next step was not as decisive, and three markers (RM237, RM 215 and RM338) located on chromosomes 1, 9 and 3 respectively were needed to predict $98 \%$ of the grouping.

We determined the aromatic/non-aromatic nature of most varieties from Myanmar (Table 1). A total of 65 of the 147 accessions (44\%) were aromatic: 27 accessions among the 67 assigned to sub-population 1 (39\%), two accessions among the 4 assigned to sub-population $5 \mathrm{~A}$ (50\%), 33 accessions among the 61 assigned to subpopulation 5B (56\%), and three admixed accessions (23\%).

We genotyped two mutations (the 8 bp deletion in exon 7 and $3 \mathrm{bp}$ insertion in exon 13) known to be associated with the presence of aroma. We tested the 147 Myanmar accessions and the 31 accessions from group 5 of the reference set (Tables 1 and Additional file 1: S1). As expected, all the accessions that had either the $8 \mathrm{bp}$ deletion or the $3 \mathrm{bp}$ insertion were aromatic. However, the reverse was not true. Thirty four aromatic varieties had neither of the mutations.

It should be noted that different accessions bearing the same name or root name, which generally indicates popular varieties, sometimes corresponded to distinct varietal types, differing in terms of aroma, functional mutation, or even assignment to a sub-population (e.g. Paw San Hmwe or Ngakywe)

\section{Sequencing}

To explain the presence of accessions that were aromatic even though they did not have any of the known mutations, we sequenced the $B A D H 2$ gene. Despite using high-fidelity long read DNA polymerase and specific PCR conditions, we were not able to consistently amplify the first two exons, probably because of the very high CG content of this zone. We amplified 4842 bp from intron 2 to 3' UTR, corresponding to $65 \%$ of the gene sequence and $78 \%$ of the coding sequence.

Among the 91 sequenced accessions listed in Tables 1 and Additional file 1: S1, we identified 63 polymorphisms corresponding to 54 SNPs, eight indels, and one SSR. Among the 63 polymorphisms, 26 were singletons almost exclusively found in two varieties: Kywet Thwar (9 specific polymorphisms), and Firooz (13 specific polymorphisms) with one in Thee Htat Pin Khine and two in Bu Saba. Nipponbare itself carried the minor allele at two SNPs, one of which was a singleton. Among the polymorphisms detected, very few were in the coding sequence: three SNPs adjacent to one 8 bp deletion in exon 7, one SNP in exon 9 (singleton in a non-aromatic accession), one SNP in exon 10 (singleton in an aromatic accession), and one $3 \mathrm{bp}$ insertion in exon 13. One SNP, one 4 bp insertion (singleton in a non-aromatic accession) and one 43 bp deletion were located in exon 15 in the 3'UTR region based on the MSU annotation, but, based on the annotation by Chen et al. (2008) were located after the end of the gene.

After eliminating the singletons and the SSR, we obtained 36 polymorphisms representing 15 haplotypes (Table 3). Six haplotypes were variety specific. Again, two corresponded to Kywet Thwar (H10) and Firooz (H11). The other four corresponded to Bay Kyar (H12), which appeared to have recombined at the end of the sequence, Nga Cheik (H13), Bu Saba (H14) and Nipponbare (H15). The remaining nine haplotypes were used to draw the haplotype network (Figure 2A and B). Two groups of haplotypes were detected ( $\mathrm{H} 1$ to $\mathrm{H} 5$ and $\mathrm{H} 6$

A

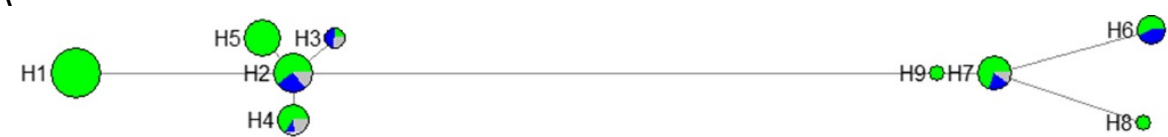

B

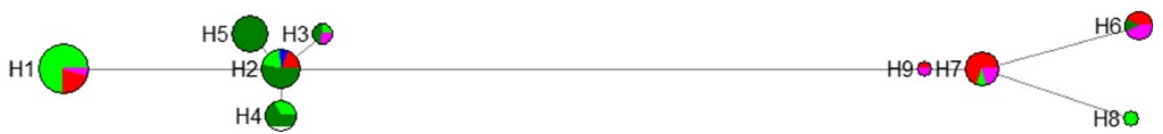

$\square$ Indica $\square \quad 5 A \quad \square \quad$ Admixed

Figure 2 Haplotype network for the gene $B A D H 2$ Each node represents a haplotype, its size being proportional to its frequency. $2 \mathrm{~A}$.

Distribution according to the aromatic nature of the accessions Green: aromatic; blue: non-aromatic; gray: unknown $\mathbf{2 B}$. Distribution according to Structure groups Red: 1 (indica); blue: 6 (japonica); light green = 5A; dark green=5B; violet: admixed. 
to H9). In the first group, H1 included only aromatic accessions that carried the well known 3 SNPS -8 bp deletion polymorphism. H5 was also strictly composed of aromatic varieties that carried the $3 \mathrm{bp}$ insertion which appeared to be specific to Myanmar accessions. The other haplotypes in the first group, which did not carry mutations in the coding sequence, were composed of a mixture of aromatic and non-aromatic accessions. In the second group, mutations in the coding sequence were found only at the very end of the last exon and did not correlate with the presence of fragrance (composite haplotypes). Few haplotypes were specific to a structure group; $\mathrm{H} 8$ was specific to $5 \mathrm{~A}$ accessions (but included only two accessions), and H5 was strictly specific to $5 \mathrm{~B}$ accessions.

A total of 24 accessions from Myanmar were aromatic but did not carry any mutations in the coding sequence of the segments sequenced in this study. They belonged to different haplotypes and different varietal groups (12 from group 1, 9 from group 5B, and 3 admixed). In addition, the three accessions from Madagascar belonging to group 5A (Kiriminy 1133, Kiriminy de 4 mois, and Kiriminy type Bengaly) did not carry any mutation.

\section{Discussion}

We analyzed the genetic diversity of 147 accessions from Myanmar at neutral markers as well as the $B A D H 2$ gene, which is responsible for aroma.

Based on isozymes, Khush et al. (2003) classified the 1354 accessions from Myanmar stored in the IRRI genebank and found $1115(82.4 \%)$ belonging to group 1 (indica), $17(1.3 \%)$ to group $2,52(3.8 \%)$ to group 5,30 (2.2\%) to group 6 (japonica) and 140 (10.3\%) to group 0 (intermediates). In comparison with this representation in the reference world collection, our set clearly overrepresented group 5 accessions and under-represented japonica and intermediates, in accordance with our focus on aromatic rices.

Our analyses led to unexpected and original results, both in terms of varietal groups and distribution of aromatic varieties.

The results of Structure and of the distance-based NJ tree clearly separated group 5 accessions into two subgroups. These two sub-groups carry diagnostic alleles on at least two SSR loci located on different chromosomes, eliminating the possibility that this could result from miscoding. The accessions in group $5 \mathrm{~A}$ originate from a range of countries along the Himalayan foothills, while the accessions in group $5 \mathrm{~B}$ appear to be limited to Myanmar. The fact that this group had not been identified previously is probably due to the small number of Myanmar accessions in earlier studies. This result shows the interest of broadening the samples analyzed with molecular markers to obtain a finer view of the genetic structure of $O$. sativa. The broadest systematic study to date remains the initial isozyme survey reported in 1987-1988. While proposing group 5 as a new group comprising varieties previously considered to be Indicas, the author of that study commented on the loose coherence of this group with a geographic cline placing Myanmar varieties at the eastern edge, with a near-specific allele at locus Amp3; yet this was the only locus with this pattern, providing insufficient grounds for distinguishing sub-groups on the basis of multi-locus linkage disequilibrium. The SSR survey of 3000 accessions in the Generation Challenge Programme and the sequencing of 10000 accessions by Beijing Genomics Institute and IRRI will undoubtedly fill this gap (McNally, IRRI, personal communication).

The position of $A m p 3$ has not yet been clearly defined on the rice genome; based on recombination mapping, it should be located between 5.5 and $7.5 \mathrm{Mb}$ on chromosome 6 , but a clear association with an annotated gene in the region remains to be established. RM510, whose polymorphism clearly separates $5 \mathrm{~A}$ from $5 \mathrm{~B}$, is located on chromosome 6 , in position $2.8 \mathrm{Mb}$, i.e. approximately 3 to $5 \mathrm{Mb}$ from Amp3; linkage disequilibrium between two loci (Amp3 and Est2) on chromosome 6 was highlighted long ago, as was its relation to varietal classification (Glaszmann 1988).

Among the Myanmar accessions, a very high proportion $(44 \%)$ is aromatic. This high proportion was expected because our sampling focused on aromatic accessions. What is more surprising is the very high proportion of aromatic accession in group 1. The proportion (39\%) is almost as high as in groups 5A and 5B (50 and $56 \%$ ). Low yield is the main concern in aromatic varieties belonging to group 5 (Singh et al. 2000), while rice top yielders in tropical irrigated conditions are generally indica varieties. The development of new aromatic varieties with an indica background is difficult using varieties from group 5 as donors because of inter-group compatibility problems. The identification of many new aromatic varieties belonging to group 1 may considerably broaden the range of varieties that breeders can use.

We sequenced part of the $B A D H 2$ gene in most of the aromatic accessions of our sample. The diversity of the gene has already been studied in depth by Kovach et al. (2009), who identified 10 aroma-associated alleles. Among the polymorphisms affecting the coding sequence in our sample, we found two mutations, the 3 SNPs/ 8 bp deletion (badh2.1) and 3 bp insertion (badh2.8) already identified by these authors. But the $3 \mathrm{bp}$ insertion was present at a much higher frequency in our sample. It was recently demonstrated that this insertion did not modify the gene expression but the addition of a tyrosine to the peptide interfered with cofactor NAD + binding, lowered enzyme activity and 
led to accumulation of acetyl-pyrroline, although at a lower level than in accessions carrying the 8 bp deletion (Vanavichit and Yoshihashi 2010, Wongpanya et al. 2011, Myint et al. 2012). We found one additional deletion of $43 \mathrm{bp}$ at the very end of the gene in 22 accessions that was specific to Myanmar accessions. It is unclear whether this mutation is in the 3'UTR or outside the gene since the two annotations we used differed on exactly where exon 15 ends. However, the mutation does not control the production of aroma since the group includes both aromatic and nonaromatic accessions.

The $3 \mathrm{bp}$ insertion is typical of Myanmar aromatic accessions belonging to group 5B. It is present in the most popular and widely grown aromatic varieties such as Paw San Hmwe and its declinations (Paw San Yin, Paw San Bay Kyar). The same situation was encountered among Chinese accessions with a specific allele that has not yet been found elsewhere (Shi et al. 2008). This suggests that the trait was selected on several occasions. While the 8 bp deletion was quite successful, since it is encountered in a large diversity of countries from Madagascar to China and in various genetic backgrounds (isozyme group 5A mostly but also groups 1 and 6), the 3 bp insertion appears to have remained more localized, i.e. limited to Myanmar and group 5B. This may be due to limited past varietal exchanges between Myanmar and neighboring countries but this hypothesis is unlikely since the $8 \mathrm{bp}$ deletion was found in some of the indica aromatic accessions from Myanmar. It may result from the presence of this allele in less interesting backgrounds than those of the successful $8 \mathrm{bp}$ deletion, or from a lower expression of the aroma due to the different nature of the mutations (amino acid addition in the case of the $3 \mathrm{bp}$ insertion allele versus stop codon in the case of the 8 bp deletion allele).

Several aromatic accessions did not carry any mutation in the coding segments we sequenced. The reality of their aromatic nature can thus be questioned. Simple and fast methods such as the sniffing method or the one proposed by Sood and Siddiq (1978) are commonly used and have been shown to be in very good agreement with gas chromatography (Lorieux et al. 1996) but false positives and false negatives (because of the transient nature of aroma expression) are known to occur. In addition, the link between aroma and acetyl-pyrroline is not always direct. Some varieties can be aromatic despite a low level of acetyl-pyrroline, probably because of higher levels of other compounds (Sakthivel et al. 2009). The Kiriminy varieties from Madagascar (group 5A) that do not carry the 8 bp deletion mutation are nevertheless said to be aromatic (N. Ahmadi, Cirad, personal communication) but whether the aroma comes from acetylpyrroline or from another compound has not yet been determined.
Assuming that the great majority of those accessions are indeed aromatic, the mutations are located either in the unsequenced coding part or in the promoter. However, only two rare mutations (singletons), both specific to tropical japonicas, were found by Kovach et al. (2009) in the first and second exons that we did not sequence. Shi et al. (2008) found a 7 bp deletion in exon 2 but the deletion appeared to be specific to Chinese accessions. The possibility that the functional mutation in those aromatic accessions differs from those already described cannot be ignored. A few accessions that did not have functional $B A D H 2$ mutation that could explain their aromatic nature were also detected in previous studies (Kovach et al. 2009; Sakthivel et al. 2009). Fitzgerald et al. (2008) postulated that production of acetyl pyroline could be driven by alleles at two different genes and not only by different alleles of $B A D H 2$. Rice has indeed a second $B A D H 1$ gene located on chromosome 4 that codes for the $B A D H$ enzyme and acts in a similar way to $B A D H 2$ but is regulated differently. A minor QTL for aroma 1 was detected by Lorieux et al. (2000) on the same region of chromosome 4. Singh et al. (2010) found a haplotype of $B A D H 1$ associated with aroma. However, they also showed that the mutation in $B A D H 2$ (whose expression is constitutive) was a primary requirement and that BADH1 mostly appeared to modify aroma intensity. But the acetyl-pyrroline biosynthesis pathway is complex and mutations in other genes than $B A D H$ paralogues may be responsible for the aroma, as suggested by Sakthivel et al. (2009). The development of mapping populations involving accessions that do not carry known mutations in $B A D H 2$ as a parent could help solve this issue.

\section{Conclusion}

With one new group and the new alleles found in Myanmar, our study illustrates that the Himalayan foothills contain series of non-Indica and non-Japonica varietal types that bear novel variations for useful traits. These new alleles can be of interest for both local and more general plant breeding programs.

\section{Additional file}

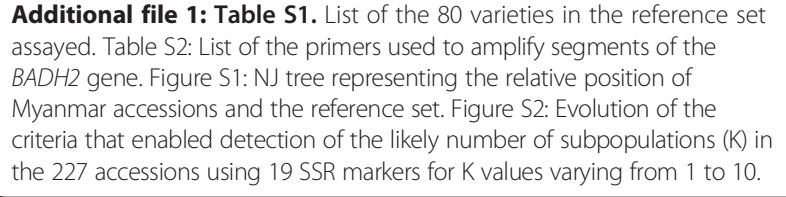

Additional file 1: Table S1. List of the 80 varieties in the reference set assayed. Table S2: List of the primers used to amplify segments of the $B A D H 2$ gene. Figure S1: NJ tree representing the relative position of Myanmar accessions and the reference set. Figure S2: Evolution of the criteria that enabled detection of the likely number of subpopulations $(K)$ in the 227 accessions using 19 SSR markers for K values varying from 1 to 10 .

\section{Competing interests}

The authors declare that they have no competing interests. 


\section{Authors' contributions}

AV, BC and JCG designed the research; KS and KMT provided the seed samples and the information on the accessions, and determined their aromatic nature. KMM, AMR and JF were involved in genotyping and sequencing data production. KMM, BC, and JCG analyzed the data and drafted the paper. All authors read and approved the final manuscript.

\section{Acknowledgments}

The authors gratefully acknowledge the Thailand International Cooperation Agency (TICA), the Thailand Research Fund (TRF) and the French Embassy in Thailand for the fellowship attributed to Ms Myo Myint in the framework of Thai-French Trilateral Development Cooperation under the Royal Golden Jubilee Programme, and the Generation Challenge Programme for support to JCG. The authors also thank Mrs D. Goodfellow for editing the manuscript.

\section{Author details}

${ }^{1}$ Plant Biotechnology Center, Myanma Agriculture Service, Yangon, Myanmar. ${ }^{2}$ Cirad, UMR AGAP, Avenue Agropolis, 34398 Montpellier, France. ${ }^{3}$ Department of Agricultural research, Yezin, Nay Pyi Taw, Myanmar. ${ }^{4}$ Rice Science Center and Rice Gene Discovery, Kasetsart University, Kamphaeng Saen, Nakhon Pathom 73140, Thailand.

\section{Received: 24 December 2011 Accepted: 16 May 2012} Published: 1 August 2012

\section{References}

Bandelt HJ, Forster P, Rohl A (1999) Median-joining networks for inferring intraspecic phylogenies. Mol Biol Evol 16:37-48.

Bourgis F, Guyot R, Gherbi H, Tailliez Al, Salse J, Lorieux M, Delseny GA (2008) Characterization of the major fragrance gene from an aromatic japonica rice and analysis of its diversity in Asian cultivated rice. Theor Appl Genet 117:353-368.

Bradbury LMT, Fitzgerald TL, Henry RJ, Jin Q, Waters DLE (2005) The gene for fragrance in rice. Plant Biotechnol J 3:363-370.

Bradbury LMT, Gillies SA, Brushett DJ, Waters DLE, Henry RJ (2008) Inactivation of an aminoaldehyde dehydrogenase is responsible for fragrance in rice. Plant Mol Biol 68:439-449.

Breiman L, Friedman JH, Olshen R, Stone CJ (1984) Classification and regression trees. Wadsworth and Brooks, Pacific Grove, California.

Buttery RG, Ling LC, Juliano BO (1982) 2-Acetyl-1-pyrroline: an important aroma component of cooked rice. Chem Ind (London) 23:958-959.

Chen S, Yang Y, Shi W, Ji Q, He F, Zhang Z, Cheng Z, Liu X, Xu M (2008) Badh2, encoding betaine aldehyde dehydrogenase, inhibits the biosynthesis of 2-acetyl-1-pyrroline, a major component in rice fragrance. Plant Cell 20:1850-1861.

Evanno G, Regnaut S, Goudet J (2005) Detecting the number of clusters of individuals using the software STRUCTURE: a simulation study. Mol Ecol 14:2611-2620.

Excoffier L, Laval G, Schneider S (2006) Arlequin v3.1. An integrated software for population genetic data analysis., http://cmpg.unibe.ch/software/arlequin3.

Fitzgerald MA, Sackville Hamilton NR, Calingacion MN, Verhoeven HA, Butardo VM (2008) Is there a second fragrance gene in rice? Plant Biotechnol J 6:416-423.

Garris AJ, Tai TH, Coburn J, Kresovich S, McCouch S (2005) Genetic structure and diversity of O. sativa. Genetics 169:1631-1638.

Gay F, Maraval I, Roques S, Gunata Z, Boulanger R, Audebert A, Mestres C (2010) Effect of salinity on yield and 2-acetyl-1-pyrroline content in the grains of three fragrant rice cultivars in Camargue. Field Crop Res 117:154-160.

Glaszmann J-C (1987) Isozymes and classification of Asian rice varieties. Theor Appl Genet 74:21-30.

Glaszmann J-C (1988) Geographic pattern of variation among Asian native rice cultivars based on fifteen isozyme loci. Genome 30:782-792.

Glaszmann J-C, Arraudeau M (1986) Rice plant type variation: Japonica-Javanica relationships. Rice Genet Newsl 3:41-43.

Glaszmann J-C, Mew T, Hibino H, Kim CK, Mew TI, Vera Cruz CH, Notteghem J-L, Bonman JM (1995) Molecular variation as a diverse source of disease resistance in cultivated rice. In: Rice Genetics III. IRRI, Los Baños, Philippines, pp 460-466.

Juliano BO (2007) Rice chemistry and quality. Philrice, Philippines, p 402.

Kato S, Kosaha H, Hara S (1928) On the affinity of rice varieties as shown by the fertility of rice plants. Bull Sci Central Agric Kyushu Imperial Univ 2:241-276.
Khush GS, Brar D, Virk PS, Tang SX, Malik SS, Busto GA, Lee YT, McNally R, Trinh LN, Jiang Y, Shat MAM (2003) Classifying rice germplasm by isozyme polymorphism and origin of cultivated rice. In: IRRI Discussion Paper 46., p 279.

Kovach MJ, Calingacion MN, Fitzgerald MA, McCouch SR (2009) The origin and evolution of fragrance in rice. PNAS 106(34):14444-14449.

Liu K, Muse SV (2005) PowerMarker: Integrated analysis environment for genetic marker data. Bioinformatics 31(9):2128-2129.

Lorieux M, Petrov M, Huang N, Guiderdoni E, Ghesquière A (1996) Aroma in rice: genetic analysis of quantitative trait. Theor Appl Genet 93:1145-1151.

Matsuo T (1952) Genecological studies on cultivated rice. Bull Natl Inst Agric Sci Jpn 3:1-111.

Myint KM, Arikit S, Wanchana S, Yoshihashi T, Choowongkomon K, Vanavichit A (2012) A PCR-based marker for a locus conferring the aroma in Myanmar rice (Oryza sativa L.). Theor Appl Genet: , DOI 10.1007/s00122-012-1880-0.

Niu X, Tang W, Huang W, Ren G, Wang Q, Luo D, Xiao Y, Yang S, Wang F, Lu BR, Gao F, Lu T, Liu Y (2008) RNAi-directed down-regulation of OsBADH2 results in aroma (2-acetyl-1-pyrroline) production in rice (Oryza sativa L.). BMC Plant Biol 8:100.

Oka HI (1958) Varietal variation and classification of cultivated rice. Ind J Genet Plant Breed 18:78-79.

Perrier X, Jacquemoud-Collet JP (2006) DARwin software.: , http://darwin.cirad.fr/.

Petrov M, Danzart M, Giampaoli P, Fayre J, Richard H (1996) Rice aroma analysis. Discrimination between a scented and non-scented rice. Sci Aliment 16:347-360.

Pritchard JK, Stephens M, Donnelly P (2000) Inference of population structure using multilocus genotype data. Genetics 155:945-959.

Risterucci AM, Grivet L, N'Goran JAK, Pieretti I, Flament MH, Lanaud C (2000) A high density linkage map of Theobroma cacao L. Theor Appl Genet 101:948-955.

Roy R, Steffens DL, Gratside B, Jang GY, Brumbaugh JA (1996) Producing STR locus patterns from bloodstains and other forensic samples using an infrared fluorescent automated DNA sequencer. J Forensic Sci 41:418-424.

Sakthivel K, Sundaram RM, Rani NS, Balachandran SM, Neereja CN (2009) Genetic and molecular basis of fragrance in rice. Biotechnol Adv 27:468-473.

Shi W, Yang Y, Chen S, Xu M (2008) Discovery of a new fragrance allele and the development of functional markers for the breeding of fragrant rice varieties. Mol Breed 22:185-192.

Singh RK, Singh US, Khush GS (2000) Aromatic rices. Oxford and IBH Publishing Co, New Delhi, India, p 292.

Singh A, Singh PK, Singh R, Pandit A, Mahato AK, Gupta DK, Tyagi K, Singh AK, Singh NK, Sharma TR (2010) SNP haplotypes of the BADH1 gene and their association with aroma in rice (O. sativa L.). Mol Breed 26:325-338.

Sood BG, Siddiq EA (1978) A rapid technique for scent determination in rice. Indian J Genet Plant Breed 38:268-271.

Tun YT (2006) Characterization of Myanmar rice landraces based on analyses of genetic diversity of various traits. PhD thesis. Tokyo University of Agriculture, Japan, p 248.

Unnevher L, Duff B, Juliano BO (1992) Consumer demand for rice grain quality. IRRI, Manila Philippines and IDRC, Ottawa, Canada, p 248.

Vanavichit A, Yoshihashi T (2010) Molecular aspects of fragrance and aroma in rice. Adv Bot Res 56:49-73.

Vanavichit A, Tragoonrung S, Toojinda T, Wanchana S, Kamolsukyunyong W (2008) Transgenic rice plants with reduced expression of Os2AP and elevated levels of 2-acetyl-1-pyrroline. US patent 7(319):181.

Wongpanya R, Boonyalai N, Thammachuchourat N, Horata N, Arikit S, Myint KM, Vanavichit A, Choowongkomon K (2011) Biochemical and enzymatic study of rice $B A D H$ wild-type and mutants: an insight into fragrance in rice. Protein J 30:529-538.

Wright S (1978) Evolution and the genetics of populations. Variability within and among natural population. University of Chicago Press, Chicago, p 590

Yamanaka S, Jatoi SA, Yi SS, Kothari SL, Htut T, Watanabe KN (2011) Genetic diversity of Myanmar rice and their implementation on management methods. Afr J Biotechnol 10(8):1290-1298.

\section{doi:10.1186/1939-8433-5-20}

Cite this article as: Myint et al:: Specific patterns of genetic diversity among aromatic rice varieties in Myanmar. Rice 2012 5:20. 